E. YEN-PON, P. A. CHAMPAGNe, L. PlOUGASTEL, S. GABILlET, P. THUÉRY, M. JOHNSON, G. MULLER, G. PIETERS, F. TARAN, K. N. HOUK, D. AUdiSIO* (UNIVERSITÉ PARISSACLARY, GIF-SUR-YVETTE, FRANCE AND UNIVERSITY OF CALIFORNIA, LOS ANGELES, SAN JOSÉ STATE UNIVERSITY, USA)

Sydnone-Based Approach to Heterohelicenes through 1,3-Dipolar-Cycloadditions

J. Am. Chem. Soc. 2019, 141, 1435-1440.

\title{
A New Twist on Sydnones
}

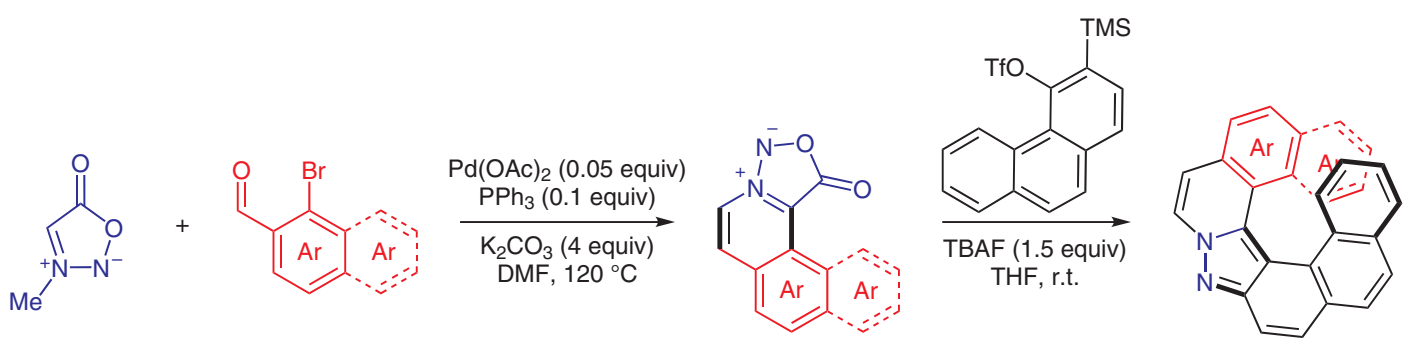

Selected examples:

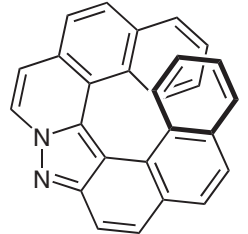

$62 \%(66 \%)$ yield

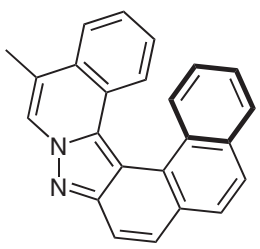

$60 \%(66 \%)$ yield

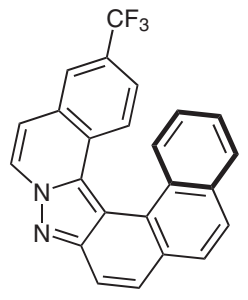

$70 \%(56 \%)$ yield

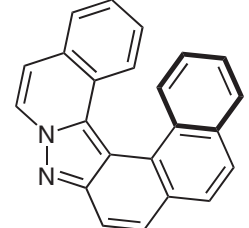

$79 \%(88 \%)$ yield

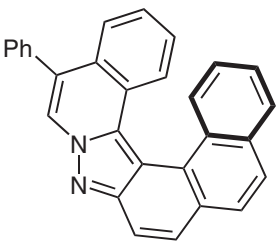

$76 \%(70 \%)$ yield

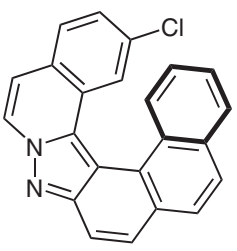

$73 \%(78 \%)$ yield

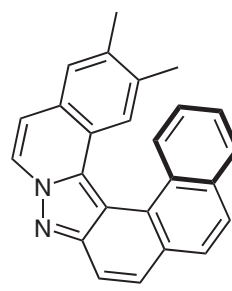

$49 \%(16 \%)$ yield

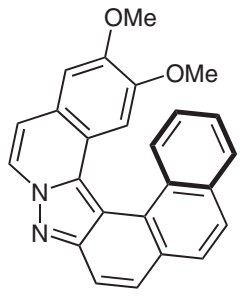

$18 \%(81 \%)$ yield

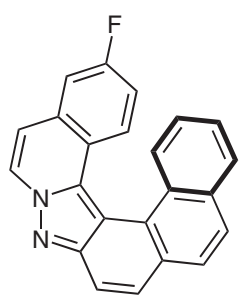

$53 \%(63 \%)$ yield

${ }^{*}$ Yields in parantheses represent yield of intermediate sydnone.

Significance: While helicenes have held the attention of chemists for years, expedient, selective syntheses to access such architectures are few and far between. In this report, Audisio and co-workers disclose a two-step method to a variety of pyrrazole-containing heterohelicenes through the cycloaddition of arynes and sydnones.
Comment: To form the helical product selectively, it was found that the phenanthryne cycloaddition partner was key. The use of naphthyne and benzyne cycloaddition partners resulted in eroded selectivity. Computational studies revealed that a $\mathrm{C}-\mathrm{H} \cdots \pi$ interaction stabilized the transition state for the helicene. 